\title{
The ETS Domain Factor Pet-1 Is an Early and Precise Marker of Central Serotonin Neurons and Interacts with a Conserved Element in Serotonergic Genes
}

\author{
Timothy Hendricks, Nicole Francis, Dmitry Fyodorov, and Evan S. Deneris \\ Case Western Reserve University, Department of Neurosciences, School of Medicine, Cleveland, Ohio 44106
}

\begin{abstract}
Serotonin (5-HT) plays a crucial neuromodulatory role in numerous physiological and behavioral functions, and dysfunction of the serotonergic system has been implicated in several psychiatric disorders. Despite the widespread importance of the central serotonergic neurotransmitter system, little is known about the molecular mechanisms controlling the development of 5-HT neurons. We previously identified an ETS domain transcription factor, Pet-1, that is expressed in a small number of tissues, including the brain. Here, we show that expression of Pet-1 RNA in the brain is restricted to, and marks, the entire rostrocaudal extent of rat serotonergic hindbrain raphe nuclei. Remarkably, Pet-1 RNA colocalizes with tryptophan hydroxylasepositive neurons in raphe nuclei but not with their nonserotonergic neuron or non-neuronal neighbors. Pet-1 RNA is limited to two domains in the developing hindbrain, which
\end{abstract}

The central serotonin (5-HT) neurotransmitter system consists of a relatively small population of morphologically diverse neurons whose cell bodies are present primarily within the limits of the midbrain-hindbrain raphe nuclei and particular regions of the reticular formation (Steinbusch, 1981). Although there are only $\sim 20,000$ serotonergic neurons in the rat brain, the extensive axonal projection system arising from these cells bears a tremendous number of collateral branches so that the 5-HT system densely innervates nearly all regions of the CNS (Jacobs and Azmitia, 1992; Halliday et al., 1995). Given its widespread distribution, it is not surprising that 5-HT has been implicated in the control of numerous neural systems, including those that mediate cognition, affect, aggression, and perception (Heninger, 1997). Abnormal function of the central 5-HT system has been implicated in several psychiatric maladies, such as depression, anxiety,

Received Aug. 4, 1999; revised Sept. 13, 1999; accepted Sept. 22, 1999.

This work was supported by National Institutes of Health, National Institute of Mental Health Grant MH58926 and National Institutes of Health, National Institute of Neurological Diseases and Stroke Grant NS29123. We thank Dr. Randy Blakely (Vanderbilt University) for communicating the sequence of a recently identified portion of the human 5-HTT promoter before publication. We thank Dr. Rula Abbud in the Nilson laboratory (Department of Pharmacology, Case Western Reserve University) for providing details of the DIG in situ hybridization method. We thank Drs. Alison Hall and Karl Herrup for use of their microscopes. We thank Mike Scott for help in the preparation of luciferase reporters and Drs. Richard Zigmond and Karl Herrup for helpful comments on this manuscript.

Drs. Hendricks and Francis contributed equally to this work.

Correspondence should be addressed to Evan Deneris, Case Western Reserve University, School of Medicine, Department of Neuroscience, 2109 Adelbert Road, Cleveland, OH 44106-4975. E-mail: esd@po.cwru.edu.

Dr. Francis's present address: Department of Molecular Biology, Massachusetts General Hospital, Boston, MA 02114.

Dr. Fyodorov's present address: Department of Biology and Center for Molecular Genetics, University of California, San Diego, La Jolla, CA 92093-0347.

Copyright (C) 1999 Society for Neuroscience 0270-6474/99/1910348-09\$05.00/0 precedes the appearance of 5-HT in each domain by approximately a half day. Conserved Pet-1 binding sites are present in or near the promoter regions of the human and mouse 5-HT1a receptor, serotonin transporter, tryptophan hydroxylase, and aromatic L-amino acid decarboxylase genes whose expression is characteristic of the serotonergic neuron phenotype. These sites are capable of supporting transcriptional activation through interactions with the Pet-1 ETS domain and can function as enhancers. Together, our findings establish Pet-1 as an early and precise marker of $5-\mathrm{HT}$ neurons and suggest that it functions specifically in the differentiation and maintenance of these neurons.

Key words: serotonin; ETS factor; raphe nuclei; transcription; binding site; neurotransmitter phenotype

and eating disorders. Moreover, this system is the target of several highly effective pharmacological agents that are used widely to treat these conditions. Despite the clear importance of the central 5-HT system in a wide range of CNS processes and clinical disorders, little is known about the genetic mechanisms that control the specification and differentiation of serotonergic neurons.

ETS domain transcription factors play important developmental roles in a variety of invertebrate and vertebrate cell lineages, most notably those of the mammalian hematopoietic system (Bassuk and Leiden, 1997). Different members of this winged helixloop-helix DNA binding protein family have been implicated in such processes as the regulation of cell proliferation, cell typespecific differentiation, programmed cell death, and oncogenic transformation (Wasylyk et al., 1993). Several ets genes are expressed in different regions of the vertebrate nervous system, which suggests that ETS factors perform neural cell type-specific functions. A particularly interesting example is that the ETS factors polyomavirus enhancer activator 3 (PEA3) and ER81 are expressed in distinct subsets of spinal motor neuron pools and in some of the muscle sensory afferent neurons that innervate them. The matching of ETS factor expression among functionally connected motor and sensory neurons is proposed to contribute to the development of specific spinal sensorimotor circuits (Lin et al., 1998). However, the particular functions of PEA3 and ER81 in these circuits and of other ETS factors expressed elsewhere in vertebrate nervous system are not yet known.

We recently identified an ets gene, Pet-1, that is expressed primarily in neural tissues, including the brain (Fyodorov et al., 1998). To begin to understand the functions Pet- 1 might perform in the nervous system, we have investigated Pet- 1 expression in 
the adult and developing brain. We find that, at all developmental ages, Pet-1 expression is limited to the hindbrain 5-HT neurotransmitter system. We also identify a conserved transcriptional cis-element present in or near genes whose expression is characteristic of mature central serotonin neurons. Together, our results suggest that Pet-1 in the brain is a key transcriptional regulator of genes required specifically for the serotonergic neuron phenotype.

\section{MATERIALS AND METHODS}

\section{Histology}

In situ hybridization. The $\left[{ }^{35} \mathrm{~S}\right]$-radiolabeled and digoxigenin (DIG)labeled Pet-1-specific antisense RNA probes for in situ hybridization analyses were prepared using as template a $1.0 \mathrm{~kb}$ fragment of our full-length Pet-1 cDNA (p73-7Z) (Fyodorov et al., 1998). This portion of the cDNA encodes an unconserved region of the Pet-1 protein beginning at an EcoN1 site just downstream of the ETS domain and continuing through the $3^{\prime}$ untranslated region. Preparation of $\left[{ }^{35} \mathrm{~S}\right]-\mathrm{Pet}-1$ probe and radiolabeled in situ hybridization were performed as described previously (Deneris et al., 1988). [ $\left.{ }^{35} \mathrm{~S}\right]$ hybridization signals from $20-30 \mu \mathrm{m}$ coronal sections of adult rat brain were obtained on Eastman Kodak (New Haven, CT) XAR film exposed at room temperature for 2-3 d.

DIG-Pet-1 probes were synthesized with digoxigenin-11-UTP according to the manufacturer's instructions (Roche, Burlington, NC). For hybridizations with DIG-Pet-1 probes, $4 \%$ paraformaldehyde-fixed adult rat brain sections mounted on Superfrost Plus slides (Fisher, Pittsburgh, PA) were acetylated in $0.35 \%$ acetic anhydride (v/v) at room temperature in $100 \mathrm{~mm}$ triethanolamine, $\mathrm{pH} 8$, for $10-15 \mathrm{~min}$ and then rinsed in $2 \times$ SSC for $5 \mathrm{~min}$. Tissue sections were then hybridized overnight at $55-65^{\circ} \mathrm{C}$ with hydrolyzed DIG-Pet-1 probe diluted 1:100 in hybridization buffer (Wada et al., 1989) without dithiothreitol. The next day, coverslips were removed in $4 \times$ SSC, and sections were treated in $1 \times$ RNase A buffer (10 mm Tris, $80 \mathrm{~mm} \mathrm{NaCl}$, and $1 \mathrm{~mm}$ EDTA, $\mathrm{pH} 8$ ) with $30 \mu \mathrm{g} / \mathrm{ml}$ RNase A (Sigma, St. Louis, MO) at $37^{\circ} \mathrm{C}$ for $30 \mathrm{~min}$, followed by incubation in $1 \times$ RNase A buffer at $37^{\circ} \mathrm{C}$ for $30 \mathrm{~min}$. Sections were then washed in $0.1 \times$ SSC at $60^{\circ} \mathrm{C}$ for $30 \mathrm{~min}$. For immunological detection of DIG-labeled hybrids, sections were first blocked in $2 \times$ SSC, $0.05 \%$ Triton X-100, and $2 \%$ normal sheep serum for $1 \mathrm{hr}$ at room temperature and rinsed twice in buffer $1(100 \mathrm{~mm}$ Tris, $\mathrm{pH} 7.4$, and $150 \mathrm{~mm} \mathrm{NaCl})$. Sections were then incubated overnight at $4^{\circ} \mathrm{C}$ in $100 \mu \mathrm{l}$ of a solution containing sheep anti-DIG-alkaline phosphatase-conjugated Fab fragments (Roche) diluted 1:1000 in buffer 1 plus $0.3 \%$ Triton X-100 and 1\% normal sheep serum under parafilm coverslips in humidified Petri dishes. The next day, sections were transferred to $37^{\circ} \mathrm{C}$ for $1 \mathrm{hr}$ and then washed twice for 15 min each in buffer 1 , followed by a 5 min equilibration in buffer 2 (300 $\mathrm{mm}$, Tris $\mathrm{pH} 9.5,300 \mathrm{~mm} \mathrm{NaCl}$, and $150 \mathrm{~mm} \mathrm{MgCl}_{2}$ ). The alkaline phosphatase chromogen reaction was performed in buffer 2 containing $340 \mu \mathrm{g} / \mathrm{ml}$ nitroblue tetrazolium (Sigma), $180 \mu \mathrm{g} / \mathrm{ml}$ 5-bromo-4-chloro3-indolyl phosphate (Sigma), and $240 \mu \mathrm{g} / \mathrm{ml}$ levimisole (Sigma) at $37^{\circ} \mathrm{C}$ for $4-5 \mathrm{hr}$ and stopped with Tris-EDTA buffer. Sections were treated with graded ethanols and xylene and mounted in DPX mounting medium (Electron Microscopy Sciences, Ft. Washington, PA).

Timed pregnant Sprague Dawley rats (Zivic Miller, Portersville, PA) were killed by $\mathrm{CO}_{2}$ asphyxiation. Embryos were staged according to Christie (1962) by a combination of somite counts and crown-to-rump measurements. Unfixed embryos were cryoprotected in $20 \%$ sucrose (w/v) in PBS, embedded in OCT (Electron Microscopy Sciences), and frozen on dry ice. Cryosections $(20 \mu \mathrm{m})$ were mounted on Superfrost Plus (Fisher) slides and used for DIG-Pet-1 in situ hybridization essentially as described previously (Schaeren-Weimers and Gerfin, 1993). Slides were washed and developed as described above for $3 \mathrm{hr}$ to $3 \mathrm{~d}$ at room temperature in the dark. Comparison of Pet-1 expression with 5-HT immunoreactivity was performed in sibling embryos. Embryos for 5-HT immunohistochemistry were fixed in $4 \%$ paraformaldehyde in PBS at $4^{\circ} \mathrm{C}$ at least $5 \mathrm{hr}$, cryoprotected in $20 \%$ sucrose in PBS at $4^{\circ} \mathrm{C}$, and sectioned as described above. Slides were air-dried for $2 \mathrm{hr}$, followed by treatment with $0.3 \% \mathrm{H}_{2} \mathrm{O}_{2}$ in water at room temperature for $30 \mathrm{~min}$. 5-HT immunohistochemistry was then performed as described below.

Combined in situ hybridization-immunohistochemistry. Sections were treated as described above for DIG-Pet-1 probe hybridization except that, after termination of the alkaline phosphatase reaction, sections were placed in water for $1 \mathrm{hr}$ and then in dilution buffer (2\% BSA, $0.3 \%$ Triton X-100, $0.1 \%$ sodium azide, and $5 \%$ sheep serum in $1 \times$ PBS) for
$1 \mathrm{hr}$ at room temperature. Sections were then treated with a 1:100 dilution of anti-tryptophan hydroxylase (TPH) monoclonal antibody (Sigma) overnight at $4^{\circ} \mathrm{C}$ in humidified Petri dishes. The next day, sections were rinsed in $1 \times$ PBS three times for $15 \mathrm{~min}$ each and then incubated for 1-2 $\mathrm{hr}$ at room temperature with a 1:100 dilution of biotinylated goat anti-rabbit IgG antibody in dilution buffer. Horseradish peroxidase reactions were performed using the avidin-biotin-peroxidase complex (Vectastain ABC kit; Vector Laboratories, Burlingame, CA.) and SigmaFast diaminobenzidine tetrahydrochloride tablets (Sigma).

Immunohistochemistry. 5-HT immunohistochemistry was performed as described for anti-TPH antibody staining with a 1:10,000 dilution of rabbit anti-5-HT antiserum (Incstar, Stillwater, MN).

Slides were photographed on Leica (Nussloch, Germany) or Nikon (Tokyo, Japan) microscopes. Images of embryos were digitally collected using a SPOT camera (Diagnostic Instruments, Sterling Heights, MI). All photomicrographs were prepared using Adobe Systems (San Jose, CA) Photoshop except x-ray film autoradiograms, which were photographed and printed.

\section{Electrophoretic mobility shift assay}

Pet-1 was expressed in and purified from bacteria (Fyodorov and Deneris, 1996). For EMSA with recombinant Pet-1, 200 ng of Pet-1 was incubated with a $200-400 \mathrm{M}$ excess of unlabeled competitors for $20 \mathrm{~min}$ at room temperature in $1 \times$ TGE $(50 \mathrm{~mm}$ Tris, $380 \mathrm{~mm}$ glycine, and $2 \mathrm{~mm}$ EDTA), $30 \mathrm{~mm} \mathrm{KCl}, 4 \mathrm{~mm} \mathrm{MgCl}_{2} 5 \%$ glycerol, with $10.5 \mu \mathrm{g} \mathrm{BSA}$, and 1 $\mu \mathrm{g} \mathrm{dI} \cdot \mathrm{dC}$; total reaction volume was adjusted to $14 \mu \mathrm{l}$ with water. Radiolabeled probe $(0.1 \mathrm{pmol})$ was added, and the reactions were further incubated $10 \mathrm{~min}$ at $37^{\circ} \mathrm{C}$. Reactions were separated on $6 \%$ acrylamide $-2 \%$ glycerol-0.5 $\times$ TGE gels as described above and exposed 12-24 hr to a phosphorimager screen (Molecular Dynamics, Sunnyvale, CA).

\section{Transfections}

Plasmids. The adenovirus major late promoter (MLP) was introduced into pGL2basic (Promega, Madison, WI) to make MLP-luc. This plasmid was used to prepare reporters that have four copies of different Pet-1 binding sites shown in Table 1 , which were placed upstream of the promoter using SacI-XhoI polylinker sites. 4x-m5HTT(-2024)-luc was made by subcloning duplex $5^{\prime}$-cCAC AGG GAG GAA ATG CAA GAC Ac-3', followed by two cycle multimerization using SacI, XhoI, and EcoRI restriction sites. 2x-h5HTT( $-1154,-1174)$-luc was prepared by subcloning duplex 5'-cTCA CTG CTA TTT CCT TTC GGT CTT CTA CTT CCT ATC GTT C, followed by one cycle multimerization. 4x5HT1a-luc was prepared by subcloning duplex 5'-CAA GCA GGA AGT TCC AAG CAG GAA GTT CCA AGC AGG AAG TTC CAA GCA GGA AGT TC. mut4x5HT1a-luc was prepared by subcloning duplex 5'-CAA GCA tac AGT TCC AAG CAt acA GTT CCA AGC Ata cAG TTC CAA GCA tac AGT TC. Synthetic oligonulceotides were obtained from Life Technologies (Gaithersburg, MD). All reporters were sequenced through the cloning region to verify the sequence of introduced oligonucleotides. Cytomegalovirus (CMV)-Pet-VP16 was prepared by subcloning into pCGS (Fyodorov and Deneris, 1996) the Pet-1 cDNA sequences encoding amino acids 146-229 upstream of VP16 sequences encoding amino acids 411-490. The linker sequence between Pet- 1 residues and VP16 residues is VEEFPGI. The SV40 nuclear localization signal is positioned at the $\mathrm{N}$ terminus of the fusion protein.

Retinal cell culture and transfections. Retinas were dissected from postnatal day 1 rat pups and dissociated in $5 \mathrm{mg} / \mathrm{ml}$ dispase (Roche) for 5 min. After a rinse in DMEM (Celox, St. Paul, MN) with $10 \%$ heat-inactivated fetal bovine serum (HyClone, Logan, UT), retinas were triturated with a fire-polished Pasteur pipette in serum-containing medium with $3.5 \%$ BSA (Life Technologies,) and plated at $\sim 5 \times 10^{5}$ cells per well of poly-L-lysine $(0.1 \mathrm{mg} / \mathrm{ml})$ (Sigma) and laminin $(1 \mu \mathrm{g} / \mathrm{ml})(\mathrm{Life}$ Technologies) coated 24-well plates. Cultures were plated in the same media but changed to serum-free medium after $\sim 24 \mathrm{hr}$. Serum-free medium consisted of DMEM (Celox) supplemented with insulintransferrin-selenium (Sigma), penicillin-streptomycin, $0.1 \mathrm{mg} / \mathrm{ml}$ sodium pyruvate (Sigma), BSA (1.5\%), and $10 \mathrm{ng} / \mathrm{ml}$ recombinant human BDNF (Peprotech, Rocky Hill, NJ). Cultures were allowed to grow for $3 \mathrm{~d}$ before transfection. Calcium phosphate transfections were performed essentially as described previously (Xia et al., 1996). Reporter DNA (2 $\mu \mathrm{g})$ and $1 \mu \mathrm{g}$ CMV-Pet-1-VP16 effector were used per transfection for luciferase assays, which were performed $24 \mathrm{hr}$ after transfection. PC12 cell transfections were performed by electroporation as described previously (Yang et al., 1994). 

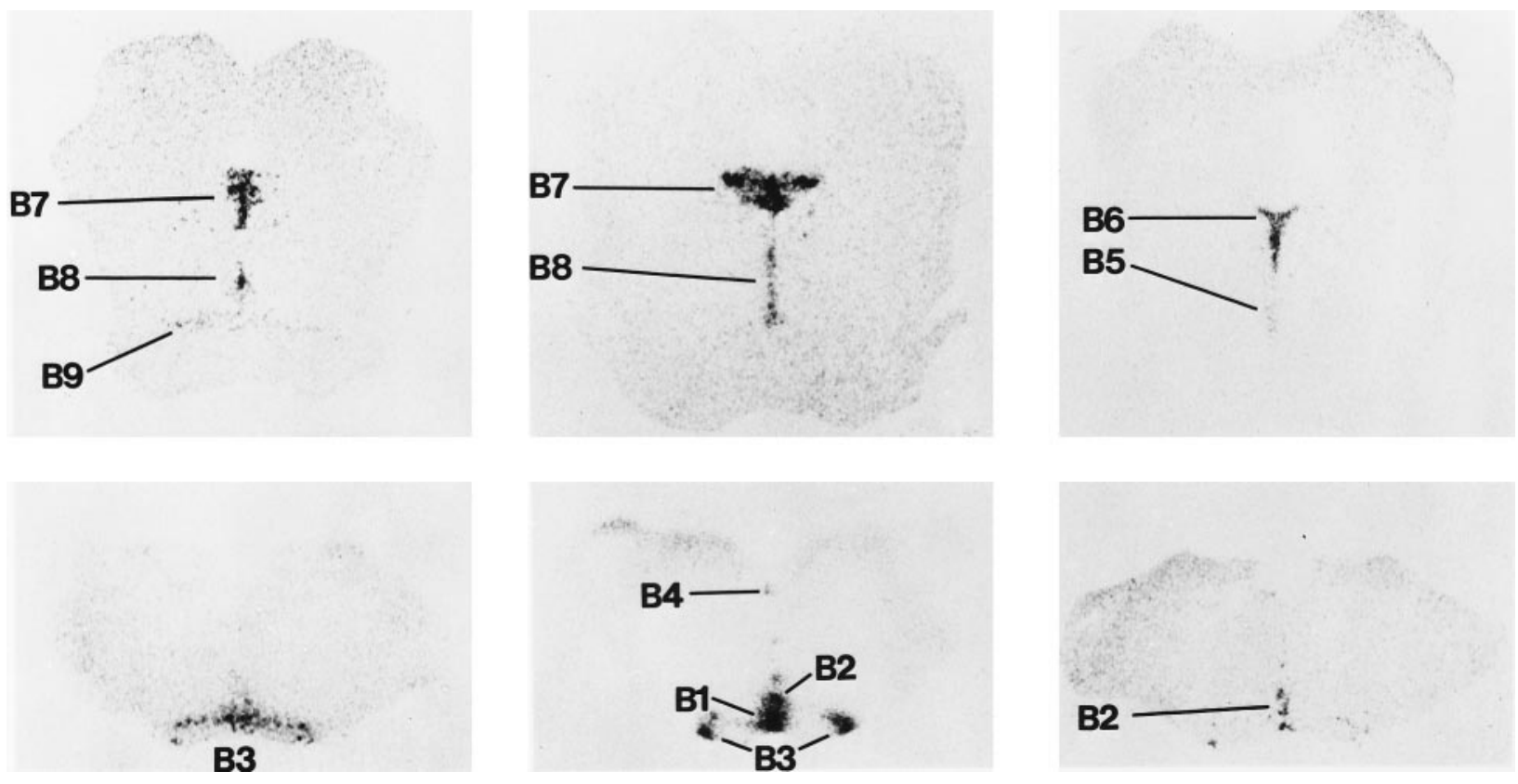

Figure 1. Pet-1 RNA is expressed in the B1-B9 groups of central serotonergic neuron clusters. The data are presented as x-ray film autoradiography of $\left[{ }^{35} \mathrm{~S}\right]$-labeled probe in coronal sections of adult rat brain. Analyses of several rat brains from olfactory bulbs to spinal cord did not reveal other sites of Pet-1 RNA expression in the adult rat brain. $B 1$, Raphe pallidus and caudal ventrolateral medulla; $B 2$, raphe obscurus; $B 3$, raphe magnus, rostral ventrolateral medulla, and lateral paragigantocellular reticular nucleus; $B 4$, central gray of the medulla oblongata; $B 5$, pontine median raphe nucleus; $B 6$, pontine dorsal raphe nucleus; $B 7$, midbrain dorsal raphe nucleus; $B 8$, midbrain median raphe nucleus; $B 9$, medial lemniscus.

\section{RESULTS}

\section{Expression of the Pet-1 gene in the central 5-HT system}

In situ hybridization was used to determine the spatial distribution of Pet-1 RNA in rat brain. Pet-1 RNA was detected in a small number of scattered midline nuclei in the midbrain-hindbrain region, which correspond to the $\mathrm{B} 1-\mathrm{B} 9$ groups of the midline raphe nuclei (B1, B2, B4-B8) and their lateral extensions (B3, B9) (Fig. 1). No other sites of Pet-1 expression could be identified in brain or spinal cord. Serotonergic neurons within the B1-B9 groups are intermingled with a substantial number of nonserotonergic neurons and glia (Jacobs and Azmitia, 1992). To determine whether Pet-1 gene expression is limited to serotonergic neurons in raphe nuclei, we compared Pet-1 RNA distribution with 5-HT immunoreactivity on adjacent sections in the region of the midbrain dorsal (B7) and median (B8) raphe nuclei. The general distribution of Pet-1 RNA in these nuclei is strikingly similar to that of 5-HT immunoreactivity (Fig. $2 A, B$ ). For example, clear clustering of Pet-1 RNA is evident in the median raphe, as well the dorsal, ventral, and lateral serotonergic neuron fields of the dorsal raphe. Pet-1 RNA was not detected outside of these fields. To confirm colocalization of Pet-1 RNA to serotonergic neurons, Pet-1 in situ hybridization was combined with immunohistochemistry for TPH, the rate-limiting enzyme for 5-HT biosynthesis, on single sections. We find that Pet-1 colocalizes with all TPH-positive neurons in the dorsal raphe nucleus, as well as with isolated TPH-positive neurons located more laterally in the central gray (Fig. 2C,D).

\section{Pet-1 expression in the developing hindbrain}

To determine whether Pet-1 might function in the development of the central 5-HT system, we investigated its pattern and onset of expression in the embryonic brain. In the developing brain, the 5-HT system is parceled into two subdivisions: the rostral (supe- rior) and caudal (inferior) clusters (Lidov and Molliver, 1982; Wallace and Lauder, 1983; Aitken and Tork, 1988). Both clusters extend longitudinally on either side of the floor plate along the ventral aspect of the neural tube. The developing rostral cluster gives rise to 5-HT neurons comprising the B4-B9 groups. These groups provide the majority of ascending serotonergic fibers to the forebrain. The caudal cluster generates 5-HT neurons that will become the B1-B3 groups and provides the major descending 5-HT projection to the spinal cord. The rostral cluster appears first, showing 5-HT immunoreactivity in the rhombencephalon caudal to the mesencephalic flexure at embryonic day 13 (E13) (see Fig. 4D) (Wallace and Lauder, 1983; Aitken and Tork, 1988). The caudal cluster of 5-HT neurons appears at least $1 \mathrm{~d}$ later and is located in the myelencephalon, caudal to the pontine flexure (see Fig. 4H) (Lidov and Molliver, 1982; Wallace and Lauder, 1983; Aitken and Tork, 1988).

Significantly, in E14.0 sagittal sections, two longitudinal domains of Pet-1 expression were detected: one beginning just caudal to the mesencephalic flexure and extending to the apex of the pontine flexure, and the other caudal to the pontine flexure (Fig. 3A). In transverse sections through the rostral cluster, Pet-1 expression at E14.0 occurs adjacent to the floor plate primarily at the outer boundary of the ventricular zone, although some expression is detected within the mantle zone (Fig. 3B,C).

The temporal relationship between Pet-1 expression and the appearance of 5-HT was then determined in the developing brain. The earliest age at which Pet-1 expression could be detected was E12.5 when a small number of isolated Pet-1-positive cells were seen just caudal to the mesencephalic flexure within the ventricular zone (data not shown); at E12.75, significantly greater numbers of Pet-1-positive cells were seen at the outer boundary of the ventricular zone (Fig. 4A). By E13.0, Pet-1 RNA expression on sagittal sections appears as a longitudinal band caudal to the mesencephalic flexure (Fig. 4B, arrow, $C$ ), and the first 5-HT- 


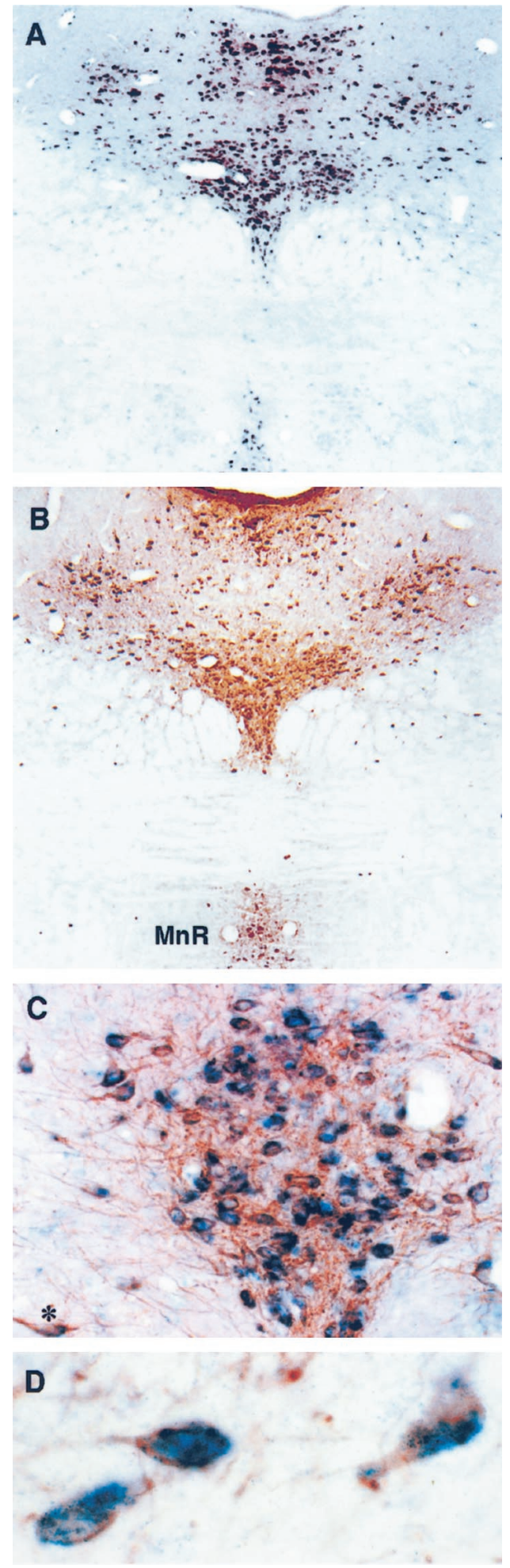

Figure 2. Pet-1 expression in brain is restricted to serotonergic neurons. $A, B$, DIG-Pet-1 antisense RNA probes were used to the compare the distribution of Pet-1 RNA $(A)$ with that of 5-HT immunoreactivity $(B)$ in adjacent $20 \mu \mathrm{m}$ coronal sections through adult dorsal and median raphe. $C$, Double-label analysis at the level of the ventral field of the dorsal raphe using DIG-Pet-1 RNA probe and a monoclonal antibody raised against rabbit TPH. $D$, Higher magnification photomicrograph of Pet-1-positive and TPH-positive neurons. Dark blue reaction product represents Pet-1 RNA, and brown reaction product represents TPH immunoreactivity. $M n R$, Median raphe. Asterisk, Isolated double-labeled neuron in the reticular formation. Magnifications: $A, B, 30 \times ; C, 220 \times ; D, 675 \times$.
A
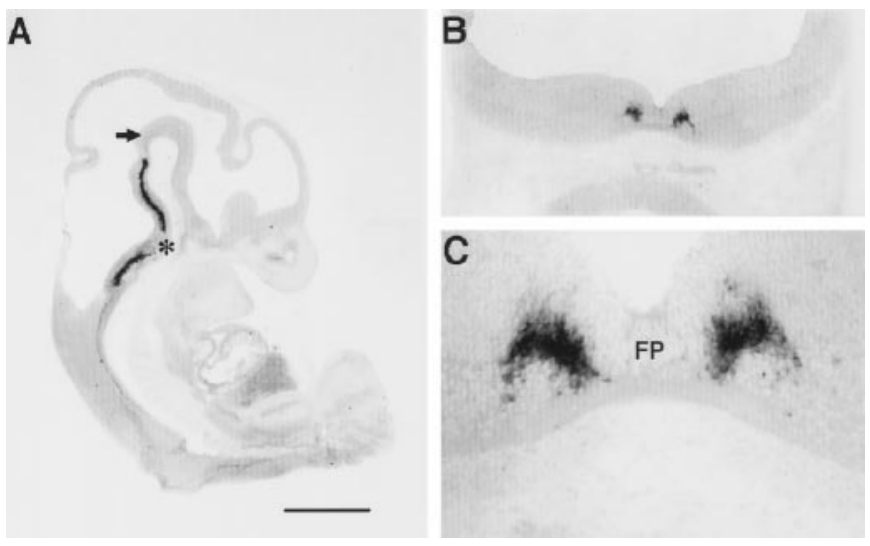

Figure 3. Pet-1 is expressed in the developing hindbrain. A, In situ hybridization for Pet-1 with digoxigenin-labeled Pet-1 RNA probe at E14.0. Hybridization of a sagittal section close to the midline indicates two domains of Pet-1 expression with one just caudal to the mesencephalic flexure (arrow) and the other caudal to the pontine flexure (asterisk). $B, C$, Hybridization of a transverse section of neural tube at E14.0 shows Pet-1 expression in a bilateral cluster (top), which is located adjacent to the floor pate and near the outer surface of the ventricular zone (bottom). FP, Floor plate. Scale bar: $A, 1.5 \mathrm{~mm} ; B, 300 \mu \mathrm{m} ; C, 37.5 \mu \mathrm{m}$.

positive cells were now evident in this same region (Fig. 4D). At this age, neither Pet-1 (Fig. 4B) nor 5-HT (data not shown) could be detected in the area caudal to the pontine flexure. By E13.5, the rostral expression domain of Pet-1 has expanded and is now accompanied by a second longitudinal band caudal to the pontine flexure (Fig. 4E, arrow, F). At this age, however, 5-HT immunoreactivity is not yet present in the caudal domain (Fig. 4G, arrow) and is not detected in the caudal region until E14.0 (Fig. $4 H$, arrow). At later ages, more 5-HT neurons appear in the caudal cluster (data not shown) (Lidov and Molliver, 1982), matching the expression domain of Pet-1 at E14.0. The data shown in Figures 3 and 4 indicate, therefore, that similar to the appearance of 5-HT, Pet-1 expression occurs at two different stages in two spatially distinct domains in the developing hindbrain. The two Pet-1 domains correspond precisely to the location of the developing rostral and caudal 5-HT neuron clusters (Lidov and Molliver, 1982; Wallace and Lauder, 1983). In each cluster, however, the onset of Pet-1 expression precedes the appearance of 5-HT by $\sim 0.5 \mathrm{~d}$.

\section{Identification of a conserved Pet-1 binding site in serotonergic genes}

The specific expression pattern of Pet-1 in the developing hindbrain beginning before the appearance of 5-HT and continuing in the adult suggests that Pet-1 functions to establish and maintain the serotonergic phenotype. This led us to wonder whether Pet-1 might directly interact with the regulatory regions of genes whose expression is characteristic of the serotonergic phenotype. To investigate this idea, we searched for Pet- 1 binding sites in or near the promoter regions of several human and mouse serotonergicspecific genes. ETS domain factors bind to sequences containing a GGAA/T core. However, specific sequences spanning several positions on either side of this core motif are obligatory for binding and discrimination among various members of the ETS domain family (Wasylyk et al., 1993). We had shown previously that Pet-1 can bind to a PEA3 ETS binding site (Martin et al., 1988; Fyodorov et al., 1998), and therefore we used this sequence as the basis for our search. At least one PEA3-like sequence was identified within $2.5 \mathrm{~kb}$ from the transcription start sites of both 
E12.75
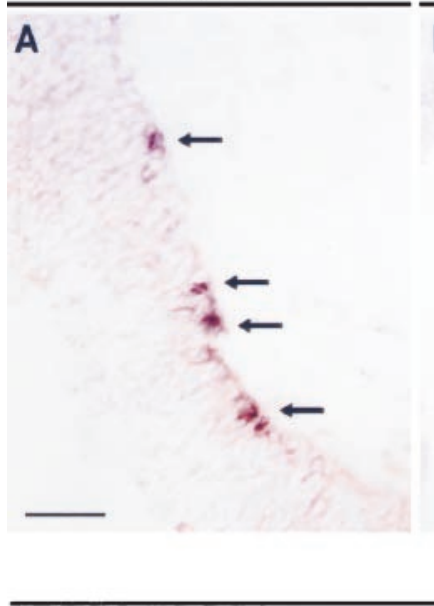

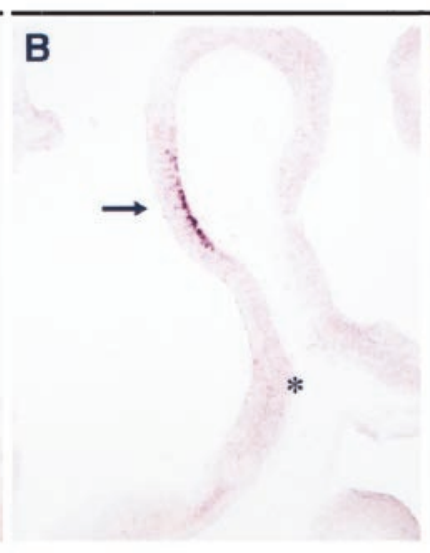

E13.5
E13.0
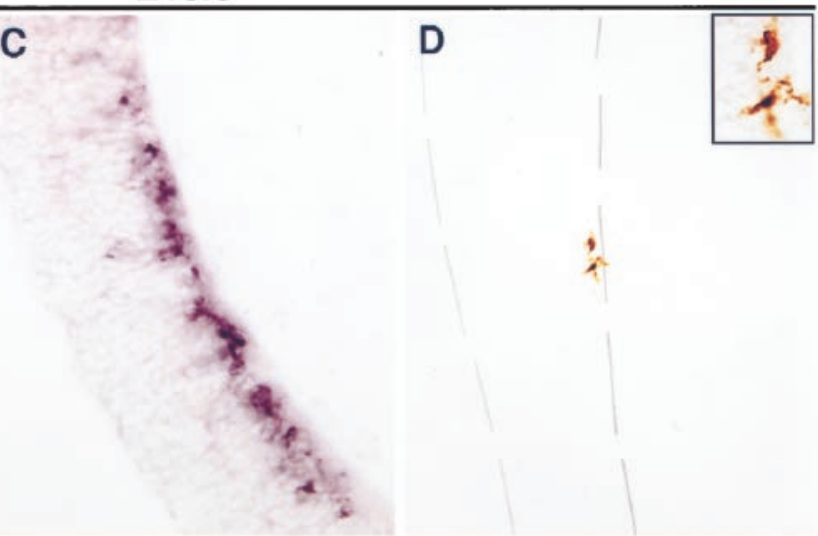

E14.0

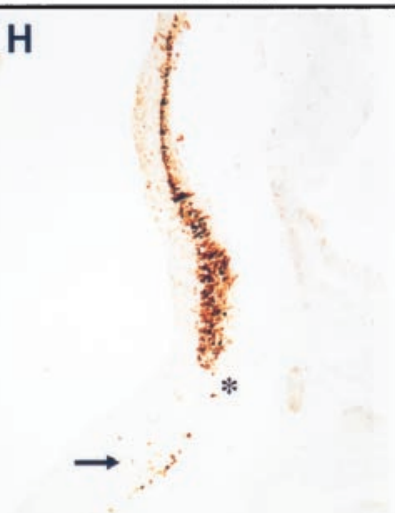

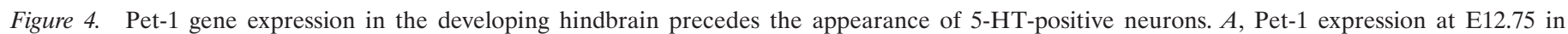

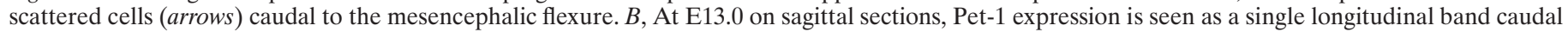

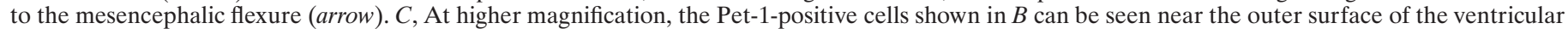

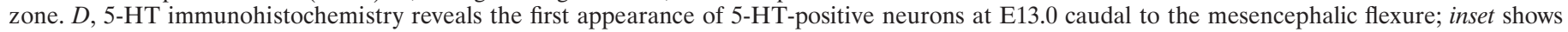

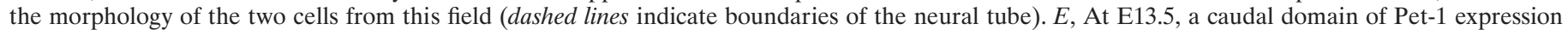

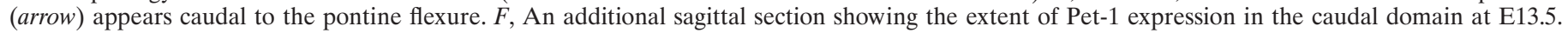

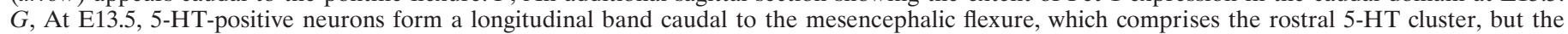

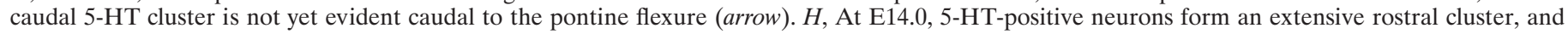

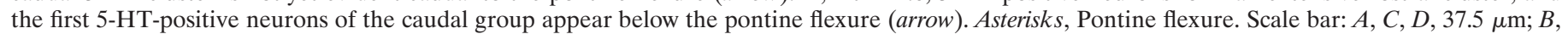
$E-H, 225 \mu \mathrm{m}$; inset in $D, 15 \mu \mathrm{m}$.

the human and mouse 5-HT1a receptor (Parks and Shenk, 1996), serotonin transporter (5-HTT) (Heils et al., 1998; Flattem and Blakely, 1999; Mortensen et al., 1999), and TPH genes (Stoll and Goldman, 1991; Boularand et al., 1995). Additionally, a PEA3like sequence was found in the large first intron of the human aromatic L-amino acid decarboxylase gene, which encodes an enzyme required for 5-HT synthesis (Table 1). Each of these sites bound to Pet-1 in mobility shift assays (Fig. 5). The specificity of binding was established by showing that incubation of a molar excess of unlabeled PEA3 oligonucleotides could eliminate complex formation between each of the probes and Pet-1 but not by incubation with altered oligonucleotides in which ETS factor interactions are prevented (Fig. 5) (Wasylyk et al., 1993). The human and mouse sequences that bound Pet-1 are highly related to one another, and comparison among these sites, as well as to those sites that did not show significant Pet-1 binding (data not shown), establishes a tentative Pet-1 consensus binding site for serotonergic genes

To determine whether Pet-1 binding observed by mobility shift assay is sufficient to modulate transcription in CNS cells, we performed transient cotransfection assays in dissociated retinal cultures (Xia et al., 1996). Minimal promoter reporters carrying multimerized Pet-1 binding sites found in the upstream region of mouse and human 5-HTT genes were transfected along with an effector plasmid constructed to express the Pet-1 DNA binding domain fused to the herpes simplex virus VP16 activation domain. The VP16 activation domain was used in place of the relatively weak Pet-1 activation domain (Fyodorov et al., 1998). The chimeric effector stimulated reporter gene expression in a Pet-1 binding site-dependent manner (Fig. 6 $A$ ). These findings demonstrate that the interaction of the Pet-1 DNA binding domain with 5-HTT Pet-1 binding sites can support transcriptional activation. To test whether these sites are capable of stimulating basal transcription, we assayed the activity of reporter plasmids in which four copies of the human 5-HT1a receptor Pet-1 binding site (Table 1) were placed upstream of a minimal promoter. PC12 cells were chosen for this experiment because these cells express ETS domain genes, including Pet-1 (Fyodorov et al., 1998). Reporter expression was stimulated greater than 200 -fold in plasmids carrying multimerized Pet- 1 binding sites relative to the minimal promoter alone, but no enhancement of the promoter was seen when the GGA core of each Pet-1 binding site was 
Table 1. Pet-1 binding sites in serotonergic genes

\begin{tabular}{ll} 
Site & Sequence \\
\hline PEA3 & AGCAGGAAGTG \\
h5HT1aR $(-137 /-127)$ & AGCAGGAAGTT \\
m5HT1aR $(-142 /-132)$ & AGCGGGAAGTT \\
h5HTT $(-1172 /-1162)$ & GAAAGGAAATA \\
h5HTT $(-1154 /-1144)$ & GATAGGAAGTA \\
m5HTT $(-2424 /-2414)$ & CCCAGGAAATG \\
m5HTT $(-2024 /-2014)$ & GGGAGGAAATG \\
hTPH $(-1154 /-1144)$ & ATACGGAAATT \\
mTPH $(-790 /-780)$ & TACAGGATATA \\
hAADC $($ Intron 1$)$ & TTCAGGAAATT \\
Consensus Pet-1 & RRMAGGAARTR \\
& tttc \\
& cCg9
\end{tabular}

Candidate Pet-1 binding sites were identified based on similarity to the PEA3 site (Martin et al., 1988). The consensus binding site is based on sequences listed below, which show strong Pet-1 binding by mobility shift assay. Comparisons indicate that, in addition to the invariant GGA core, other obligatory nucleosides are thymidine at position +6 and adenosine or guanosine at position +4 . Position +1 is the first guanosine residue in the invariant core. 5HT1aR, Serotonin receptor 1a; TPH, tryptophan hydroxylase; 5HTT, serotonin transporter; AADC, aromatic L-amino acid decarboxylase. h, Human; $\mathrm{m}$, mouse. Numbers in parentheses indicate position of a Pet-1 binding site in the $5^{\prime}$ flanking region of the indicated gene. $\mathrm{R}=\mathrm{G}$ or $\mathrm{A}$, $\mathrm{M}=\mathrm{A}$ or $\mathrm{C}$. The lowercase letters indicate exceptions to the consensus.

mutated (Fig. 6B). These results demonstrate that the 5-HT1a receptor gene Pet-1 binding site can function as an autonomous enhancer element in PC12 cells.

\section{DISCUSSION}

Pet-1 is a rare example of a vertebrate transcription factor gene showing an extremely restricted neuronal expression pattern in the brain. Pet-1 expression is provocative because it appears to mark neurons comprising a single monamine neurotransmitter system, the hindbrain 5-HT system. Moreover, it is unique because it is the first transcription factor gene showing such a precise pattern in this system. The restricted expression of Pet-1 begins at its onset in the embryonic brain. We detect two Pet-1 expression domains along the anteroposterior axis of the developing hindbrain, which appear $\sim 1 \mathrm{~d}$ apart from one another.
These domains correspond to the eventual locations of the developing rostral and caudal 5-HT neuron clusters (Lauder and Bloom, 1974; Lauder et al., 1982). An additional significant feature is that its expression in each domain precedes the appearance of 5-HT in the rostral and caudal clusters by approximately a half day during the period when 5-HT neurons are being born (Lauder and Bloom, 1974). These findings, together with the presence of transcriptionally active Pet-1 binding sites in or near the promoter regions of several genes whose coordinate expression characterizes the mature serotonergic neuron phenotype, suggest that Pet- 1 is an essential component of a transcriptional program that triggers central 5-HT neuron differentiation.

\section{Pet-1 and the development of central 5-HT neurons}

The generation of 5-HT neurons in the neural tube depends, in part, on the activity of the notochord and floor plate-derived secreted signaling molecule sonic hedgehog (Shh) (Ye et al., 1998). In addition to Shh, FGF8 located in the isthmus region and FGF4 expressed in the primitive streak are postulated to form an induction center that specifies the identity and location of rostral serotonergic neurons (Ye et al., 1998). Shh, but not FGF8, is implicated in the induction of the caudal cluster of 5-HT neurons and is thought to act with unidentified secreted signaling molecules to generate the caudal 5-HT group. Dorsal and median raphe 5-HT neurons are born in the rat over a period of $4 \mathrm{~d}$ beginning at approximately E11 and peaking at E13-E14 (Lauder et al., 1982). In these nuclei, it is thought that serotonergic neuron precursors begin to produce 5-HT near the time of their last cell division (Lauder et al., 1982). The detection of Pet-1 as early as E12.5 in the rostral cluster, therefore, suggests that it is expressed in 5-HT neuron precursors during their terminal differentiation, consistent with its expression before the appearance of 5-HT.

Several transcription factors have been implicated in the development of some 5-HT neurons. Nkx2.2 and Gli2 are two downstream targets of the Shh signaling pathway that function during early stages of neurogenesis in the spinal cord, hindbrain, and midbrain (Matise et al., 1998; Briscoe et al., 1999). Elimination of the homeobox gene Nkx2.2 results in the absence of some serotonergic neurons in rhombomere 2 of the hindbrain (Briscoe et al., 1999), whereas elimination of the zinc-finger transcription

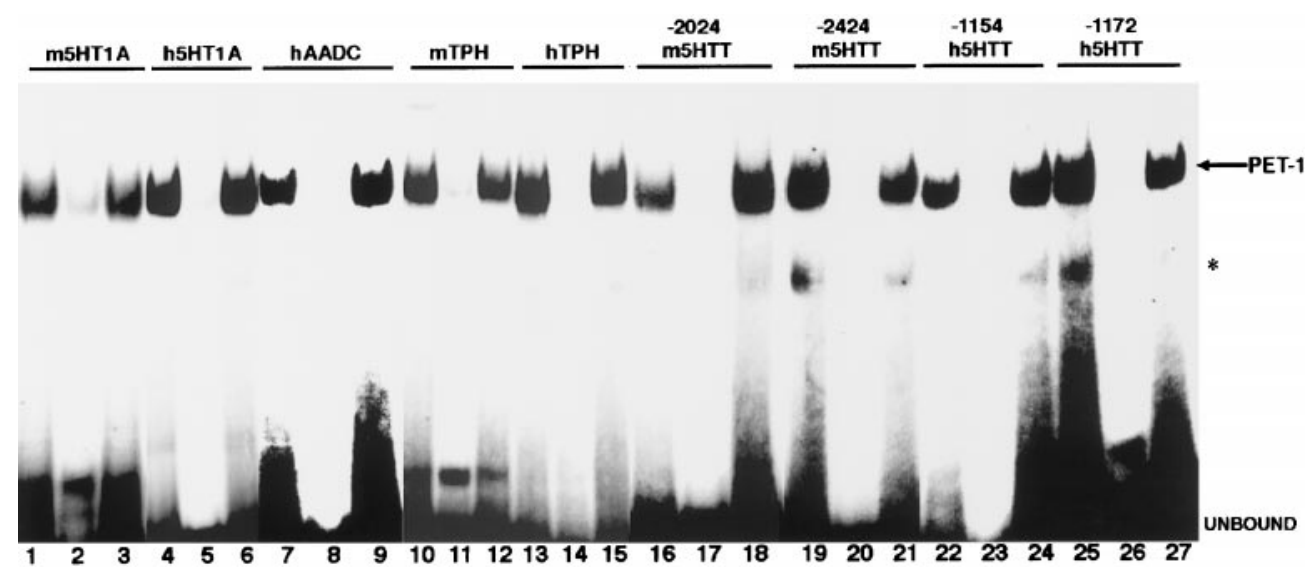

Figure 5. Identification of Pet-1 binding sites in serotonergic genes. Mobility shift assays were performed with bacterially expressed Pet-1 protein and oligonucleotides composed of sequences obtained from each of the indicated genes. The potential Pet- 1 binding site present in each of these probes is shown in Table 1. Analysis of each binding site included incubation with indicated probe and Pet-1 protein (lanes 1, 4, 7, 10, 13, 16, 19, 22, 25), competition of probe and Pet-1 protein interaction with 200-400 $\mathrm{M}$ excess of unlabeled PEA3 oligonucleotides (lanes 2, 5, 8, 11, 14, 17, 20, 23, 26), and competitions of probe and Pet-1 protein interaction with unlabeled oligonucleotides in which the 5'-GGA core of the PEA3 binding site was changed to $5^{\prime}$-TAC (lanes 3, 6, 9, 12, 15, 18, 21, 24, 27). Asterisk, Complex formed with probe and a Pet-1 protein degradation product. 

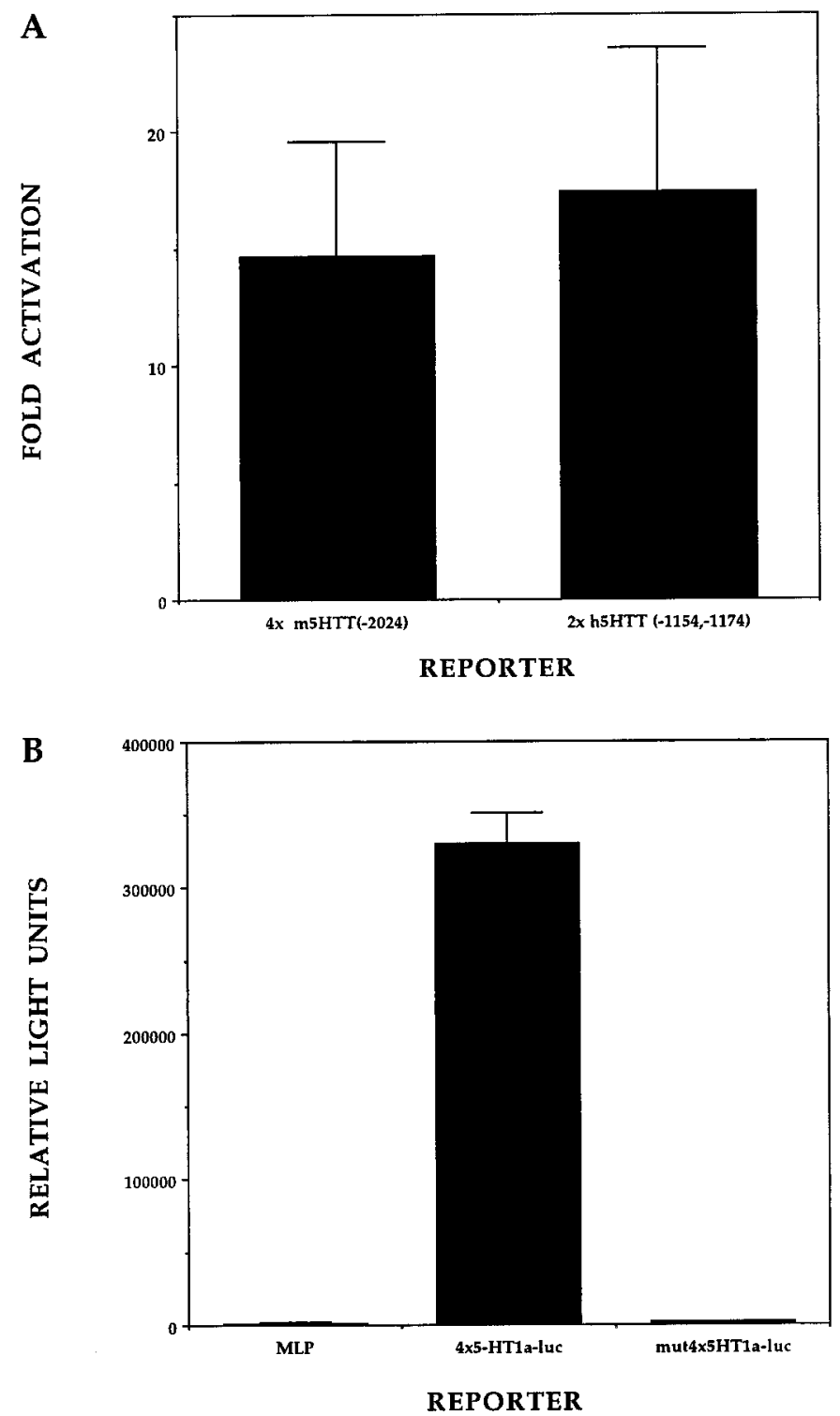

Figure 6. Functional analysis of Pet-1 binding sites. $A$, Four copies of the mouse $-2024 /-2014$ 5-HTT Pet-1 binding site and two copies of the human $-1172 /-1162 ;-1154 /-1144$ tandem Pet-1 binding site were each cloned upstream of the adenovirus 2 MLP to prepare 4xm5HTT-luc and 2xh5HTT-luc, respectively. These reporters were transfected into dissociated retinal cultures along with CMV-Pet-1-VP16 or CGS empty vector. Bars represent the ratio of Pet-1-VP16 responses of luciferase reporters containing 5-HTT binding sites over the activity of these reporters in the absence of Pet-1-VP16. This ratio included normalization to the nonspecific response of the MLP promoter by Pet-1-VP16 relative to MLP reporter alone. Error bars indicate \pm SEM. $B$, PC12 cells were transfected with reporters carrying either MLP, four copies of the 5-HT1a receptor Pet-1 binding site placed immediately upstream of MLP (4x5HT1a-luc), or four copies of the 5-HT1a receptor site upstream of MLP except that each copy had TAC residues in place of the GGA core (mut4x5HT1a-luc). Data are the average of four separate transfections for each reporter and represent the mean \pm SD relative light units.

factor Gli2 results in a partial loss and abnormal location of remaining 5-HT neurons in the ventral midline (Matise et al., 1998). GATA-3 is thought to play a role in the development of some caudal raphe nuclei. GATA-3 is expressed broadly during embryogenesis, including in many but not all 5-HT raphe neurons (van Doorninck et al., 1999). In chimeric GATA-3 homozygous null mice the organization of cells in the raphe obscurus appears altered compared with wild-type mice (van Doorninck et al., 1999). Although these transcription factors have been implicated in the development of some 5-HT neurons, they are also important for the development of many other neuronal and nonneuronal cell types. In contrast, Pet-1 is likely to be distinct from these factors because its expression pattern suggests that it performs a strictly serotonergic-specific function in the brain.

\section{Candidate downstream targets of Pet-1}

Conserved Pet-1 binding sites were identified in the promoter regions of human and mouse genes whose expression together defines serotonergic neuron identity. The Pet- 1 binding sites in the upstream regions of the human and mouse 5-HT1a raphe neuron autoreceptor (Julius, 1998) and serotonin transporter genes are positioned within previously identified regulatory regions of these genes, whereas the other binding sites are located in regions that have not yet been analyzed for transcriptional activity. The human and mouse 5-HT 1a receptor gene Pet-1 binding sites are located in the transcription start site region of their promoters (Parks and Shenk, 1996). The Pet-1 binding site at position $-2024 /-2014$ of the mouse serotonin transporter gene is located within a fragment of the upstream region that confers cell type-specific activity on a reporter gene (Heils et al., 1998). Recently, a previously unrecognized 379 bp fragment of the human serotonin transporter upstream region was reported, which is located immediately downstream of the polymorphic region associated with depression and anxiety-related traits (Flattem and Blakely, 1999; Mortensen et al., 1999). This newly reported segment was shown to contain a positive regulatory activity, although the precise sequences constituting this putative element were not reported (Mortensen et al., 1999). Interestingly, the tandem Pet-1 binding sites identified in the flanking region of the human transporter gene (Table 1) are located in this novel region and may be responsible for its positive transcriptional activity. The expression of Pet-1 before the appearance of 5-HT and its interaction with serotonergic genes are consistent with a model in which Pet-1 activates these genes. The weak transactivation activity of Pet-1 (Fyodorov et al., 1998) suggests that it may require unidentified cofactors to activate transcription, as is the case for many ETS factors (Wasylyk et al., 1993; Fitzsimmons et al., 1996). Further cell culture and transgenic analyses of the Pet-1 binding sites reported here should help to reveal whether Pet-1 or related ETS factors are common regulators of genes constituting the serotonergic neuron phenotype.

\section{Relationship of Pet-1 to other transcription factors marking particular neurotransmitter cell types}

Pet-1 is now the third reported example of vertebrate transcription factors whose expression patterns correlate with a particular neurotransmitter identity. Expression of the bicoid-related homeodomain protein Ptx3 in the brain is limited to mesencephalic dopaminergic neurons (Smidt et al., 1997). The onset of Ptx3 expression in the ventral surface of the mesencephalic flexure at E11.5 in the mouse coincides with the appearance of the first tyrosine hydroxylase-positive cells in this region of the neural tube. Ptx3 has, therefore, been proposed to be a crucial regulator of the dopaminergic phenotype (Smidt et al., 1997), perhaps in collaboration with the orphan nuclear receptor Nurr1, which has been shown to be an essential determinant of midbrain dopaminergic neuron phenotype (Zetterstrom et al., 1997).

Several lines of evidence indicate that the paired-like home- 
odomain proteins, Phox $2 \mathrm{a} /$ Arix and Phox $2 \mathrm{~b}$ are required for the development of noradrenergic neurotransmitter identity (Goridis and Brunet, 1999). These closely related proteins are expressed in all central and peripheral noradrenergic neurons just as these neurons are acquiring their differentiated phenotype (Valarche et al., 1993; Zellmer et al., 1995; Tiveron et al., 1996; Pattyn et al., 1997). Moreover, they are implicated as direct transcriptional activators of the tyrosine hydroxylase (TH) and dopamine- $\beta$ hydroxylase (DBH) genes (Zellmer et al., 1995). Phox2a/Phox2b binding sites contribute to DBH promoter activity. Expression of either factor can activate the $\mathrm{DBH}$ promoter in cell lines, and synergistic activation is observed when the cAMP pathway is stimulated in parallel with forced Arix expression (Zellmer et al., 1995; Swanson et al., 1997; Kim et al., 1998; Yang et al., 1998). Arix also binds and activates the TH promoter, but in this case, parallel stimulation of the cAMP pathway causes additive effects on transcription (Zellmer et al., 1995; Swanson et al., 1997). A dominant negative form of Phox2a, which was designed to interfere with both Phox $2 a$ and Phox $2 b$, blocks induction of endogenous $\mathrm{TH}$ and $\mathrm{DBH}$ upon treatment with bone morphogenic protein 2 and forskolin in primary neural crest cultures, whereas forced expression of wild-type Phox2a results in cAMPpotentiated induction of endogenous TH (Lo et al., 1999). Moreover, in vivo loss of function experiments demonstrate that both Phox $2 \mathrm{a}$ and Phox $2 \mathrm{~b}$ are essential determinants of the noradrenergic phenotype (Morin et al., 1997; Pattyn et al., 1999).

Our findings raise the intriguing possibility that Pet-1 functions in a manner analogous to the Phox $2 \mathrm{a}$ and Phox $2 \mathrm{~b}$. Loss or gain of function experiments should help to reveal what role Pet-1 performs in the development of the serotonergic neurotransmitter system and may create novel animal models for clinical disorders involving this system. Thus, the identification of Pet-1 expression in the hindbrain 5-HT system is likely to be an important step in elucidating the molecular mechanisms governing the development of this vital neurotransmitter pathway.

\section{REFERENCES}

Aitken AR, Tork I (1988) Early development of serotonin-containing neurons and pathways as seen in wholemount preparations of the fetal rat brain. J Comp Neurol 274:32-47.

Bassuk AG, Leiden JM (1997) The role of Ets transcription factors in the development and function of the mammalian immune system. Adv Immunol 64:65-104.

Boularand S, Darmon MC, Ravassaed P, Mallet J (1995) Characterization of the human tryptophan hydroxylase gene promoter. J Biol Chem 270:3757-3764.

Briscoe J, Sussel L, Serup P, Hartigan-O'Connor, Jessell TM, Rubenstein JLR, Ericson J (1999) Homeobox gene Nkx2.2 and specification of neuronal identity by graded sonic hedgehog signalling. Nature 398:622-627.

Christie GA (1962) Developmental stages in somite and post-somite rat embryos, based on external appearance, and including some features of the macroscopic development of the oral cavity. J Morphol 114:263-286.

Deneris ES, Connolly J, Boulter J, Wada E, Wada K, Swanson L, Patrick J, Heinemann S (1988) Primary structure and expression of beta2: a novel subunit of neuronal nicotinic acetylcholine receptors. Neuron $1: 45-54$.

Fitzsimmons D, Hodsdon W, Wheat W, Maira SM, Wasylyk B, Hagman J (1996) Pax-5 (BSAP) recruits Ets proto-oncogene family proteins to form functional ternary complexes on a B-cell-specific promoter. Genes Dev 10:2198-2211.

Flattem NL, Blakely RD (1999) Modified structure of the human serotonin transporter promoter. Mol Psychiatry, in press.

Fyodorov D, Deneris E (1996) The POU domain of SCIP/Tst-1/Oct-6 is sufficient for activation of an acetylcholine promoter. Mol Cell Biol 16:5004-5014.
Fyodorov D, Nelson T, Deneris E (1998) Cloning and expression of Pet-1, a novel ets domain factor that can activate neuronal nAchR gene transcription. J Neurobiol 32:151-163.

Goridis C, Brunet J-F (1999) Transcriptional control of neurotransmitter phenotype. Curr Opin Neurobiol 9:47-53.

Halliday G, Harding A, Paxinos G (1995) Serotonin and tachykinin systems. In: The rat nervous system (Paxinos G, ed), pp 929-974. San Diego: Academic.

Heils A, Wichems C, Mossner R, Petri S, Glatz K, Bengel D, Murphy DL, Lesch K-P (1998) Functional characterization of the murine serotonin transporter gene promoter in serotonergic raphe neurons. J Neurochem 70:932-939.

Heninger GR (1997) Serotonin, sex, and psychiatric illness. Proc Natl Acad Sci USA 94:4823-4824.

Jacobs BL, Azmitia EC (1992) Structure and function of the brain serotonin system. Physiol Rev 72:165-220.

Julius D (1998) Serotonin receptor knockouts: a moody subject. Proc Natl Acad Sci USA 95:15153-15154.

Kim H-S, Seo H, Yang C, Brunet J-F, Kim K-S (1998) Noradrenergicspecific transcription of the dopamine b-hydroxylase gene requires synergy of multiple cis-acting elements including at least two Phox2abinding sites. J Neurosci 18:8247-8260.

Lauder JM, Bloom FE (1974) Ontogeny of monamine neurons in the locus coeruleus, raphe nuclei, and substantia nigra of the rat. J Comp Neurol 155:469-482.

Lauder JM, Wallace JA, Krebs H, Petrusz P, McCarty K (1982) In vivo and in vitro development of serotonergic neurons. Brain Res Bull 9:605-625.

Lidov HGW, Molliver ME (1982) Immunohistochemical study of the development of serotonergic neurons in the rat CNS. Brain Res Bull 9:559-604.

Lin JH, Saito T, Anderson DJ, Lance-Jones C, Jessell TM, Arber S (1998) Functionally related motor neuron pool and muscle sensory afferent subtypes defined by coordinate ETS gene expression. Cell 95:393-407.

Lo L, Morin X, Brunet J-F, Anderson DJ (1999) Specification of neurotransmitter identity by Phox 2 proteins in neural crest stem cells. Neuron 22:693-705.

Martin ME, Piette J, Yaniv M, Tang W-J, Folk WR (1988) Activation of the polyomavirus enhancer by a murine activator protein 1 (AP1) homolog and two contiguous proteins. Proc Natl Acad Sci USA 85:5839-5843.

Matise MP, Epstein DJ, Park HL, Platt KA, Joyner AL (1998) Gli2 is required for induction of floor plate and adjacent cells, but not most ventral neurons in the mouse central nervous system. Development 125:2759-2770.

Morin X, Cremer H, Hirsch M-R, Kapur RP, Goridis C, Brunet J-F (1997) Defects in sensory and autonomic ganglia and absence of locus coeruleus in mice deficient for the homeobox gene Phox2a. Neuron 18:411-423.

Mortensen OV, Thomassen M, Larsen MB, Whittemore SR, Wiborg O (1999) Functional analysis of a novel human serotonin transporter gene promoter in immortalized raphe cells. Mol Brain Res 68:141-148.

Parks CL, Shenk T (1996) The serotonin 1a receptor gene contains a TATA-less promoter that responds to MAZ and Sp1. J Biol Chem 271:4417-4430.

Pattyn A, Morin X, Cremer H, Goridis C, Brunet J-F (1997) Expression and interactions of two closely related homeobox genes Phox2a and Phox2b during neurogenesis. Development 124:4065-4075.

Pattyn A, Morin X, Cremer H, Goridis C, Brunet J-F (1999) The homeobox gene Phox $2 b$ is essential for the development of autonomic neural crest derivatives. Nature 399:366-370.

Schaeren-Weimers N, Gerfin A (1993) A single protocol to detect transcripts of various types and expression levels in neural tissue and cultured cells: in situ hybridization using digoxigenin-labelled cRNA probes. Histochemistry 100:431-440.

Smidt MP, van Schaick HSA, Lanctot C, Tremblay JJ, Cox JJ, van der Kleij AAA, Wolterink G, Drouin J, Burbach PH (1997) A homeodomain gene Ptx3 has highly restricted brain expression in mesencephalic dopaminergic neurons. Proc Natl Acad Sci USA 94:13305-13310.

Steinbusch HWM (1981) Distribution of serotonin-immunoreactivity in the central nervous system of the rat-cell bodies and terminals. Neuroscience 6:557-618.

Stoll J, Goldman D (1991) Isolation and structural characterization of the murine tryptophan hydroxylase gene. J Neurosci Res 28:457-465. 
Swanson DJ, Zellmer E, Lewis EJ (1997) The homeobox protein Arix interacts synergistically with cyclic AMP to regulate expression of neurotransmitter biosynthetic genes. J Biol Chem 272:27382-27392.

Tiveron M-C, Hirsch M-R, Brunet J-F (1996) The expression pattern of the transcription factor Phox2 delineates synaptic pathways of the autonomic nervous system. J Neurosci 16:7649-7660.

Valarche I, Tissier-Seta J-P, Hirsch M-R, Martinez S, Goridis C, Brunet J-F (1993) The mouse homeodomain protein Phox2 regulates Ncam promoter activity in concert with $\mathrm{Cux} / \mathrm{CDP}$ and is a putative determinant of neurotransmitter phenotype. Development 119:881-896.

van Doorninck JH, van der Wees J, Karis A, Goedknegt E, Engel JD, Coesmans M, Rutteman M, Grosveld F, De Zeeuw CI (1999) GATA-3 is involved in the development of serotonergic neurons in the caudal raphe nuclei. J Neurosci 19:1-8.

Wada E, Wada K, Boulter J, Deneris E, Heinemann S, Patrick J, Swanson LW (1989) Distribution of alpha 2, alpha 3, alpha 4, and beta 2 neuronal nicotinic receptor subunit mRNAs in the central nervous system: a hybridization histochemical study in the rat. J Comp Neurol 284:314-335.

Wallace JA, Lauder JM (1983) Development of the serotonergic system in the rat embryo: an immunocytochemical study. Brain Res Bull 10:459-479.

Wasylyk B, Hahn SL, Giovane A (1993) The Ets family of transcription factors. Eur J Biochem 211:7-18.
Xia Z, Dudek H, Miranti CK, Greenberg ME (1996) Calcium influx via the NMDA receptor induces immediate early gene transcription by a MAP kinase-ERK-dependent mechanism. J Neurosci 16:5425-5436.

Yang C, Kim H-S, Seo H, Kim C-H, Brunet J-F, Kim K-S (1998) Paired-like homeodomain proteins, Phox2a and Phox2b, are responsible for noradrenergic cell-specific transcription of the dopamine $\beta$-hydroxylase gene. J Neurochem 71:1813-1826.

Yang X, McDonough J, Fyodorov D, Morris M, Wang F, Deneris ES (1994) Characterization of an acetylcholine receptor alpha 3 gene promoter and its activation by the POU domain factor SCIP/Tst-1. J Biol Chem 269:10252-10264.

Ye W, Shimamura K, Rubenstein JLR, Hynes MA, Rosenthal A (1998) FGF and Shh signals control dopaminergic and serotonergic cell fate in the anterior neural plate. Cell 93:755-766.

Zellmer E, Zhang Z, Greco D, Rhodes D, Cassel S, Lewis EJ (1995) A homeodomain protein selectively expressed in noradrenergic tissue regulates transcription of neurotransmitter biosynthetic genes. J Neurosci 15:8109-8120.

Zetterstrom RH, Solomin L, Jansson L, Hoffer BJ, Olson L, Perlmann T (1997) Dopamine neuron agenesis in Nurr1-deficient mice. Science 276:248-250. 